\title{
Lymphangiography is a diagnostic and therapeutic intervention for patients with plastic bronchitis after the Fontan operation
}

\author{
Shinya Ugaki, MD, PhD, ${ }^{a}$ David J. E. Lord, MBBS, FRANZCR, ${ }^{b}$ Megan C. Sherwood, MBBS, FRACP, ${ }^{a}$ \\ and David S. Winlaw, MBBS(Hons), MD, FRACS, ${ }^{\text {a }}$ Sydney Australia
}

\footnotetext{
From the ${ }^{a}$ Heart Centre for Children, ${ }^{b}$ Pediatric Interventional Radiology, Division of Medical Imaging, The Children's Hospital at Westmead, Sydney, New South Wales, Australia.

Disclosures: Authors have nothing to disclose with regard to commercial support.

Received for publication March 2, 2016; accepted for publication April 16, 2016; available ahead of print May 12, 2016.

Address for reprints: Shinya Ugaki, MD, PhD, 212 Hawkesbury Rd Westmead, NSW 2145, Australia (E-mail: shinya.ugaki@health.nsw.gov.au).

J Thorac Cardiovasc Surg 2016;152:e47-9

0022-5223/\$36.00

Crown Copyright $@ 2016$ Published by Elsevier Inc. on behalf of The American Association for Thoracic Surgery http://dx.doi.org/10.1016/j.jtcvs.2016.04.051
}

We present a patient with hypoplastic left heart who developed plastic bronchitis soon after the Fontan operation. Percutaneous lymphangiography successfully shortened the intensive care unit (ICU) stay and allowed easier palliative management.

\section{CLINICAL SUMMARY}

The patient was a 4-year-old boy diagnosed with hypoplastic left heart. He underwent a Norwood-Sano operation on day 2, a bidirectional Glenn shunt at 3 months, and a nonfenestrated extracardiac Fontan procedure at 4 years. Three months after the Fontan prodecure (2 months after discharge), he developed a persistent right pleural effusion/chylothorax and respiratory insufficiency. He coughed up bronchial casts and histopathology suggested plastic bronchitis. Medications, including nebulized tissue plasminogen activator and dornase alfa, were started. He required ventilation. Cardiac catheterization demonstrated no obstruction within the Fontan pathway or pulmonary arteries, with a mean pressure of $15 \mathrm{mmHg}$. The transesophageal echocardiogram showed normal right ventricular function with mild tricuspid regurgitation, and mild compression of a right pulmonary vein by the Fontan conduit. There was no clinical improvement despite aggressive treatment. Therefore, he underwent revision of the Fontan conduit with fenestration and patch augmentation of a small, single, right pulmonary vein. During recovery from this procedure, he had a persistent right pleural effusion, plastic bronchitis, signs of protein-losing enteropathy, and ascites. He required multiple chest drains, peritoneal drainage, and ongoing ventilator support. Heart transplantation was considered but not undertaken, and he was managed with a palliative approach.

Two months after Fontan revision, lymphangiography via bilateral inguinal lymph nodes was performed. The cisterna chyli was opacified and accessed percutaneously under

\section{DISCUSSION}

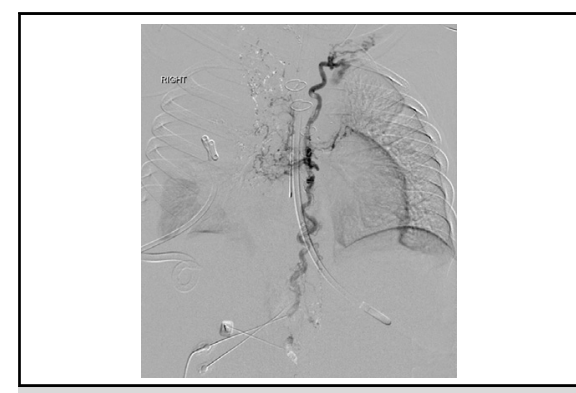

Percutaneous lymphangiography can be effective to treat plastic bronchitis

Central Message

Percutaneous lymphangiography can be effective to treat plastic bronchitis and pleural effusions after the Fontan operation in a palliative context.

See Editorial Commentary page e49.

imaging guidance using a transhepatic approach. Injection of contrast showed abnormal thoracic duct architecture with an accessory right duct refluxing contrast into right hilar and peribronchial lymphatics (Figure 1). The thoracic duct could not be selectively cannulated so the cisterna chyli was then disrupted by needle puncture. The patient tolerated the procedure without complications. His plastic bronchitis and pleural effusion resolved shortly after the lymphangiography. He was discharged to the ward 10 days after the procedure (after a 4-month ICU stay). The amount of drainage from the abdomen became transiently worse but improved 1 month after the procedure. Although his plastic bronchitis improved, he had systemic debility, was in a poor nutritional state, and had hypoxia requiring intermittent non-invasive ventilation. He was transferred home after 6 months hospitalization and died within 2 months of discharge.

The Fontan physiology renders patients vulnerable to the development of pleural effusion, protein-losing enteropathy, and plastic bronchitis. ${ }^{1-4}$ The cause of plastic bronchitis is largely unknown, but it is hypothesized that a high central venous pressure may cause a break in bronchial-mucosal integrity and impedance of lymphatic drainage, leading to lympho-alveolar fistula and bronchial 

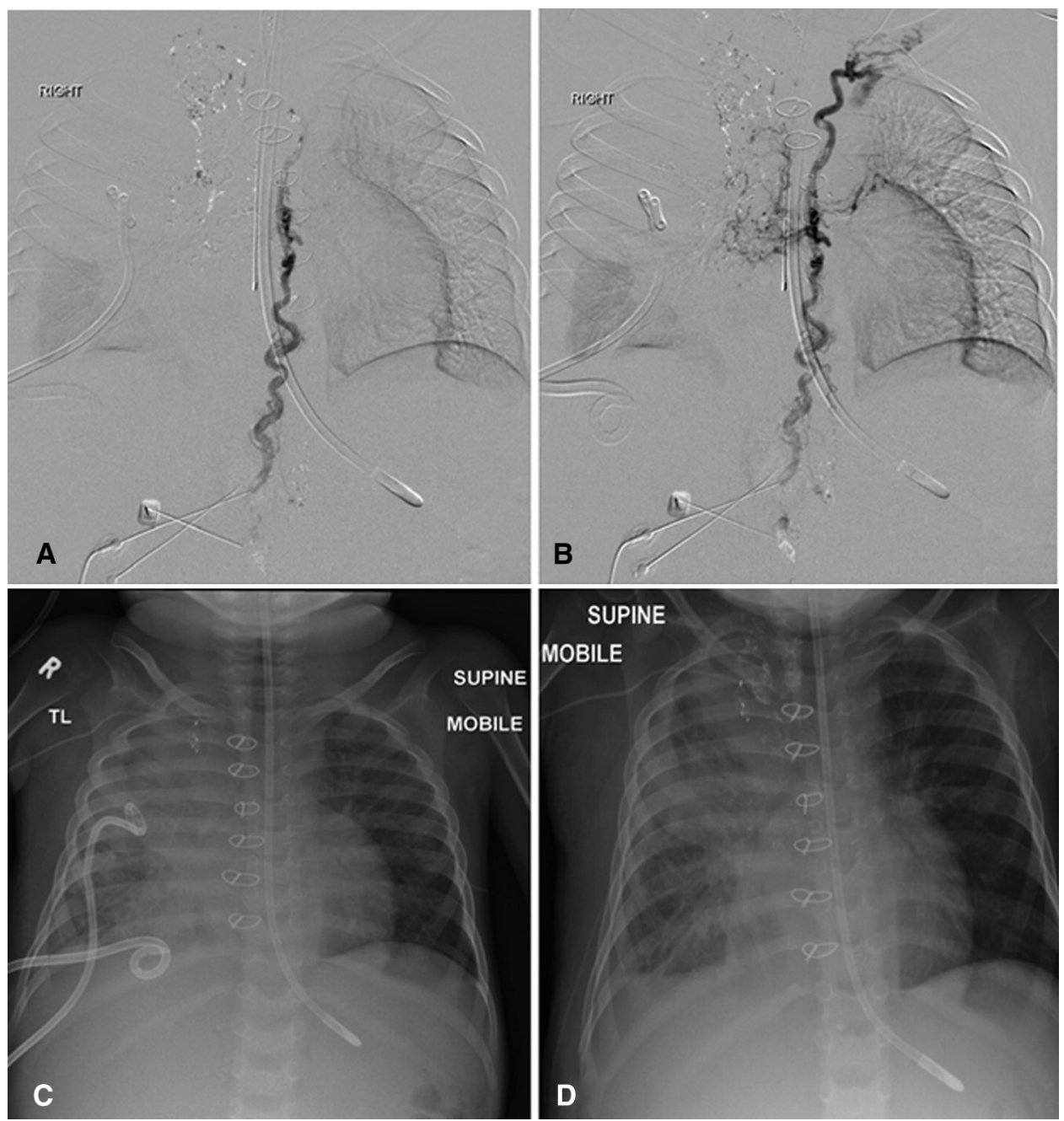

FIGURE 1. A, Contrast injection via the cisterna chyli shows the thoracic duct entering the innominate vein. B, Multiple small lymphatic collaterals from a right accessory thoracic duct flow toward the peri-bronchial network in the right hilum. $\mathrm{C}$, The chest radiograph before lymphangiography shows demarcated right pleural effusion and atelectasis. D, The improved radiograph after lymphangiography and duct disruption.

casts. ${ }^{1,3}$ Individuals appear to have different thresholds for development of plastic bronchitis because, despite similar triggers, some patients develop plastic bronchitis but others do not. Because of this, management to reduce central venous pressure, including pulmonary vasodilators and creation of a fenestration, does not always work, and transplant may be the only option.,

Recent research using magnetic resonance imaging found lymphatic abnormalities including thoracic duct dilation, lymphangiectasia, and lymphatic collaterals in many patients with single-ventricle physiology. ${ }^{2,5}$ However, experience of treating causative lymphatic and duct abnormalities is very limited. Thoracic duct ligation via thoracotomy has been used to treat plastic bronchitis, ${ }^{4}$ and percutaneous lymphatic collateral and/or thoracic duct embolization have been reported. ${ }^{1,3,5}$ The percutaneous approach can be less invasive and copes with variable duct and lymphatic anatomies more precisely. $^{1,3-5}$ Dori and colleagues demonstrated that selective collateral embolization is more advantageous because it maintains the patency of the duct. ${ }^{1}$ However, it may be challenging when there are multiple small collaterals, as in this case, or when the thoracic duct is tortuous and thus it is difficult to advance a catheter within it.

In our case, disruption of the thoracic duct was associated with resolution of both plastic bronchitis and pleural drainage, allowing progression to extubation and simplification of management. The procedure was briefly associated with an increase in ascitic drainage but this also resolved and did not require further drainage. Although plastic bronchitis was successfully treated in this case, lymphatic disruption did not alter the fundamental issues related to the failing Fontan physiology, such as protein-losing enteropathy. Further understanding of the pathologies is required in order to effectively treat these complex patients. In conclusion, percutaneous lymphangiography can show the causative lymphatic abnormalities and can be a therapeutic or 
palliative intervention for Fontan patients with plastic bronchitis in order to simplify management.

We would like to thank Dr Murthy Chennapragada and Dr John Prazas for technical help in the lymphangiography.

\section{References}

1. Dori Y, Keller MS, Rychik J, Itkin M. Successful treatment of plastic bronchitis by lymphatic embolization in a Fontan patient. Pediatrics. 2014;134:e590-5.
2. Dori Y, Keller MS, Fogel MA, Rome JJ, Whitehead KK, Harris MA. MRI of lymphatic abnormalities after functional single-ventricle palliation surgery. AJR Am J Roentgenol. 2014;203:426-31.

3. Avitabile CM, Goldberg DJ, Dodds K, Dori Y, Ravishanker C, Rychik J. A multifaceted approach to the management of plastic bronchitis after cavopulmonary palliation. Ann Thorac Surg. 2014;98:634-40.

4. Shah SS, Drinkwater DC, Christian KG. Plastic bronchitis: is thoracic duct ligation a real surgical option? Ann Thorac Surg. 2006;81:2281-3.

5. Itkin M, Krishnamurthy G, Naim MY, Bird GL, Keller MS. Percutaneous thoracic duct embolization as a treatment for intrathoracic chyle leaks in infants. Pediatrics. 2011;128:e237-41.

\section{EDITORIAL COMMENTARY}

\section{Etiology and new treatment options for patients with plastic bronchitis}

\author{
Yoav Dori, $\mathrm{MD}, \mathrm{PhD},{ }^{\mathrm{a}}$ and Maxim Itkin, $\mathrm{MD}^{\mathrm{b}}$ \\ From the ${ }^{\mathrm{a} C a r d i o l o g y}$ Department, The Children's Hospital of Philadelphia; and ${ }^{\mathrm{b}}$ Radiology Department, Hospi- \\ tal of the University of Pennsylvania, Philadelphia, Pa. \\ Disclosures: Authors have nothing to disclose with regard to commercial support. \\ Received for publication May 2, 2016; accepted for publication May 3, 2016 \\ Address for reprints: Yoav Dori, MD, PhD, Cardiology Department, The Children's Hospital of Philadelphia, 34th \\ Street and Civic Center Boulevard, Philadelphia, PA 19104 (E-mail: doriy@email.chop.edu). \\ J Thorac Cardiovasc Surg 2016;152:e49-50 \\ $0022-5223 / \$ 36.00$ \\ Copyright (C 2016 Published by Elsevier Inc. on behalf of The American Association for Thoracic Surgery \\ http://dx.doi.org/10.1016/j.jtcvs.2016.05.008
}

Ugaki and colleagues ${ }^{1}$ describe a case of a 4-year-old child diagnosed with hypoplastic left heart syndrome and plastic bronchitis (PB) that developed shortly after his Fontan operation. The patient failed conventional management, including nebulized tissue plasminogen activator and dornase alfa, and Fontan fenestration. Due to persistent symptoms of PB, bilateral groin intranodal lymphangiography was performed. Access to the cisterna chyli was obtained via the transhepatic approach and contrast injection demonstrated an accessory right duct perfusing the right hilar and peribronchial lymphatic vessels. The thoracic duct (TD) could not be selectively cannulated so disruption of the cisterna chyli was performed. The patient had an improvement in his symptoms but ultimately died as a result of hypoxia and other comorbidities.

Until recently the etiology of PB was poorly understood, although lymphatic involvement has been considered to be part of the pathologic process. ${ }^{2-4}$ Poor understanding of the disease process has led to variability in therapies across centers. Therapies have been aimed at either lowering central venous pressure

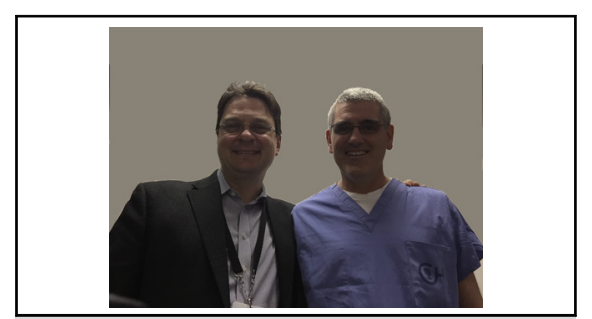

Yoav Dori, MD, PhD, and Maxim Itkin, MD

\section{Central Message}

Plastic bronchitis in patients after singleventricle palliation has a lymphatic etiology and responds to lymphatic-based treatments.

See Article page e47.

using medications such as sildenafil, applying catheter techniques such as creation of a fenestration, or they have focused on prevention of cast formation using inhaled therapies such as inhaled tissue plasminogen activator. These therapies have led to symptom improvement in some cases but usually do not lead to resolution of symptoms..$^{5}$ Heart transplantation has been reported in some cases to result in long-term resolution of symptoms but has a high mortality risk. ${ }^{6}$ Recent development of new lymphatic imaging techniques has demonstrated abnormal pulmonary lymphatic 